\title{
THE EFFECT OF ELECTROCHEMICAL MACHINING ON THE FATIGUE STRENGTH OF HEAT RESISTANCE ALLOYS
}

\author{
Jerzy Kozak \\ Institute of Aviation, Warsaw, Poland
}

\begin{abstract}
Electrochemical Machining (ECM) provides an economical and effective method for machining high strength, heat-resistant materials into complex shapes such as compressor and turbine blades, dies, molds and micro cavities. ECM is performed without physical contact between the tool and the workpiece in contrast to the mechanical machining, and without strong heating in the machining zone in distinction to the methods such as EDM. Therefore, no surface metal layer with mechanical distortion, compressive stresses, cracks, and thermal distortion forms in ECM. ECM is often used even for removing a defective layer, which has been formed in EDM, with the aim to improve the surface integrity. However, sometimes the intergranular attack occurs in ECM. This may reduce the performance of machined parts and lead to the decreasing of fatigue strength.

In this paper, the effects of ECM on fatigue strength of heat resistant alloys such as nickel-base alloys and titanium alloys are presented. The problems of the intergranular attack, hydrogen embrittlement and surface roughness as result of ECM parameters are described.
\end{abstract}

Keywords: anodic dissolution, current density, hydrogen embrittlement, intergranular attack, fatigue strength

\section{INTRODUCTION}

Electrochemical Machining (ECM) is an electrochemical anodic dissolution process in which workpiece metal is dissolved into metallic ions and thus the tool shape is copied onto the workpiece.
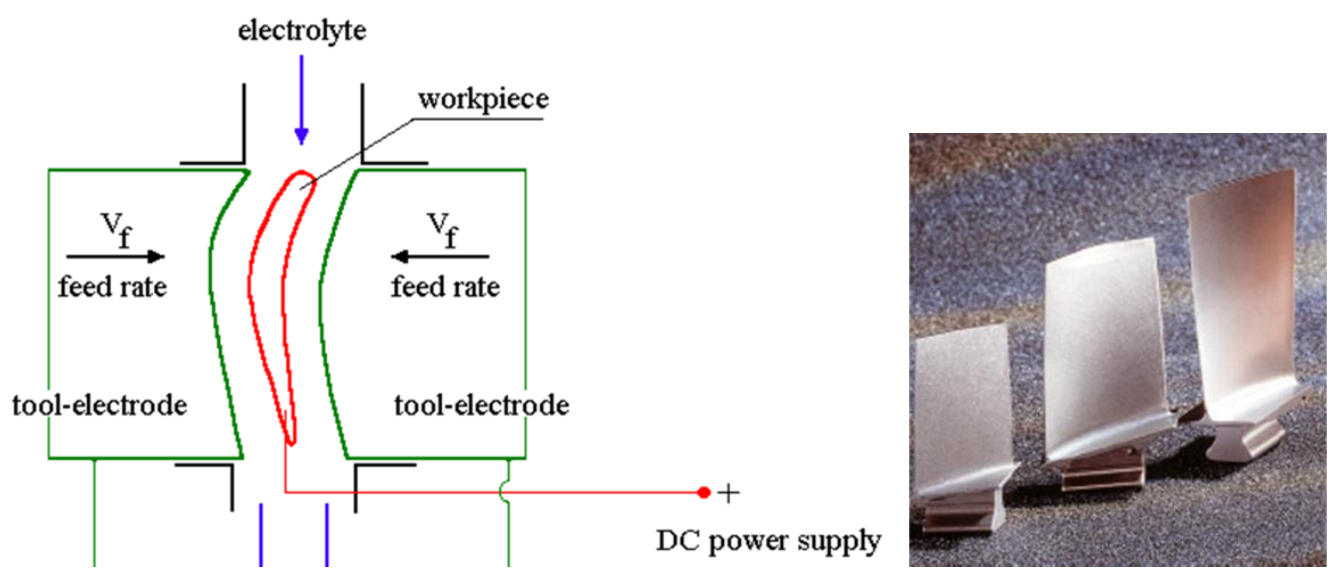

Figure 1. Principal scheme of electrochemical machining (ECM) and example of the machined airfoils 
Figure 1 illustrates the principle of machining of an airfoil-workpiece. A direct current (D.C.) voltage is applied across the interelectrode gap between a pre-shaped cathode tool electrode connected to negative polarity of power supply, and an anode-workpiece. The electrolyte (e.g. $\mathrm{NaNO}_{3}, \mathrm{NaCl}, \mathrm{KNO}_{3}, \mathrm{NH}_{4} \mathrm{NO}_{3}$, and other salt agues solutions) is forced to flow through the interelectrode gap. In typical manufacturing operations, the tool is fed toward the workpiece while maintaining a small gap.

For high accuracy in shape duplication and high rates of metal removal, the process is effected at very high current densities of the order of $10-100 \mathrm{~A} / \mathrm{cm}^{2}$, at relatively low voltage usually from 8 to $30 \mathrm{~V}$, while maintaining a very narrow machining gap (of the order of $0.1 \mathrm{~mm}$ ) by feeding the tool electrode in the direction of metal removal from the work surface, with the feed rate from 0.1 to $20 \mathrm{~mm} / \mathrm{min}$. The dissolved material (e.g. hydroxide of metal), gas, and heat are removed from the narrow machining gap by the flow of electrolyte pumped through the gap at a high velocity $(5-50 \mathrm{~m} / \mathrm{s})$.

Being a non-mechanical metal removal process, ECM is capable of machining any electricallyconductive material with high stock removal rates regardless of their mechanical properties. In particular, the removal rate in ECM is independent of the hardness, toughness and other properties of the material being machined. The use of ECM is most warranted in the manufacture of complex-shaped parts from materials that lend themselves poorly to machining by other mechanical methods. There is no need to use a tool made of a harder material than the workpiece, and there is practically no tool wear.

As mentioned above, in most modifications of ECM, the shape of the tool electrode is duplicated over the entire surface of the workpiece connected as the anode. Therefore, complexshaped parts can be produced by simply moving the tool. For this reason and also because ECM leaves no burrs, one ECM operation can replace several operations of mechanical machining. ECM removes the defective layer of the material and eliminates the flaws inherited by the surface layer from a previous treatment and usually does not generate residual stress in the workpiece. All this enhances the service qualities of the parts manufactured by ECM.

The most common uses for ECM include the following: the manufacture of turbine and compressor blades for the gas-turbine engine, duplicating, drilling and sinking operations in the manufacture of dies, press and glass-making moulds, the generation of passages, cavities, holes and slots in parts.

\section{The Effect of ECM on the Fatigue Strength of Heat Resistance Steels and Alloys}

The key factors that affect the fatigue strength of parts are surface roughness and the physical state of the surface layer. Surface roughness refers to the magnitude of microscopic irregularities. The physical state refers to structural changes, strain hardening, residual stresses, trapped gas content, etc.

In contrast to mechanical machining, the quality of surface is increased at higher stock removal rate, which can readily be increased by raising the current density (Fig.2). 


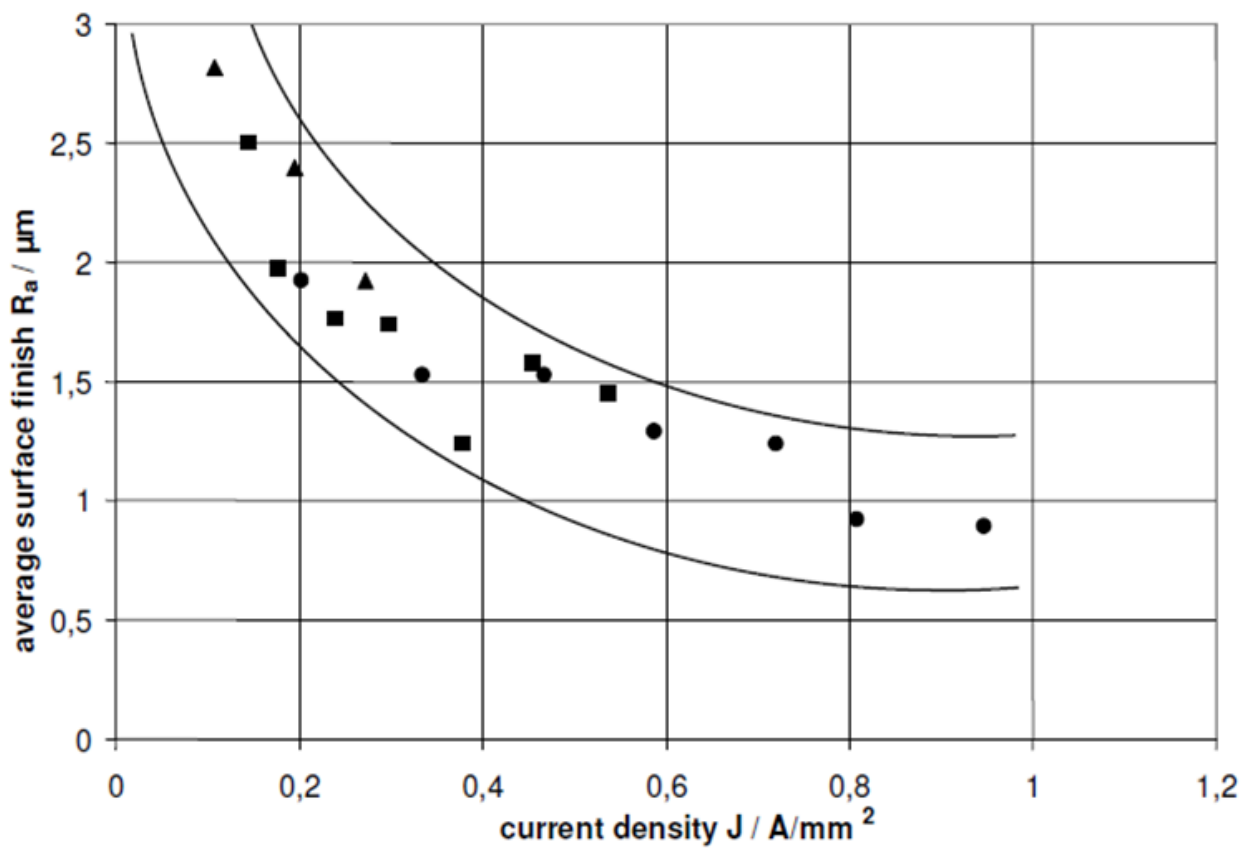

Fig.2. The effect of current density on the surface roughness: material 56NiCrMoV [1]

A better quality of the surface at higher current density leads to the increasing of the fatigue strength as shown in Figure 3.

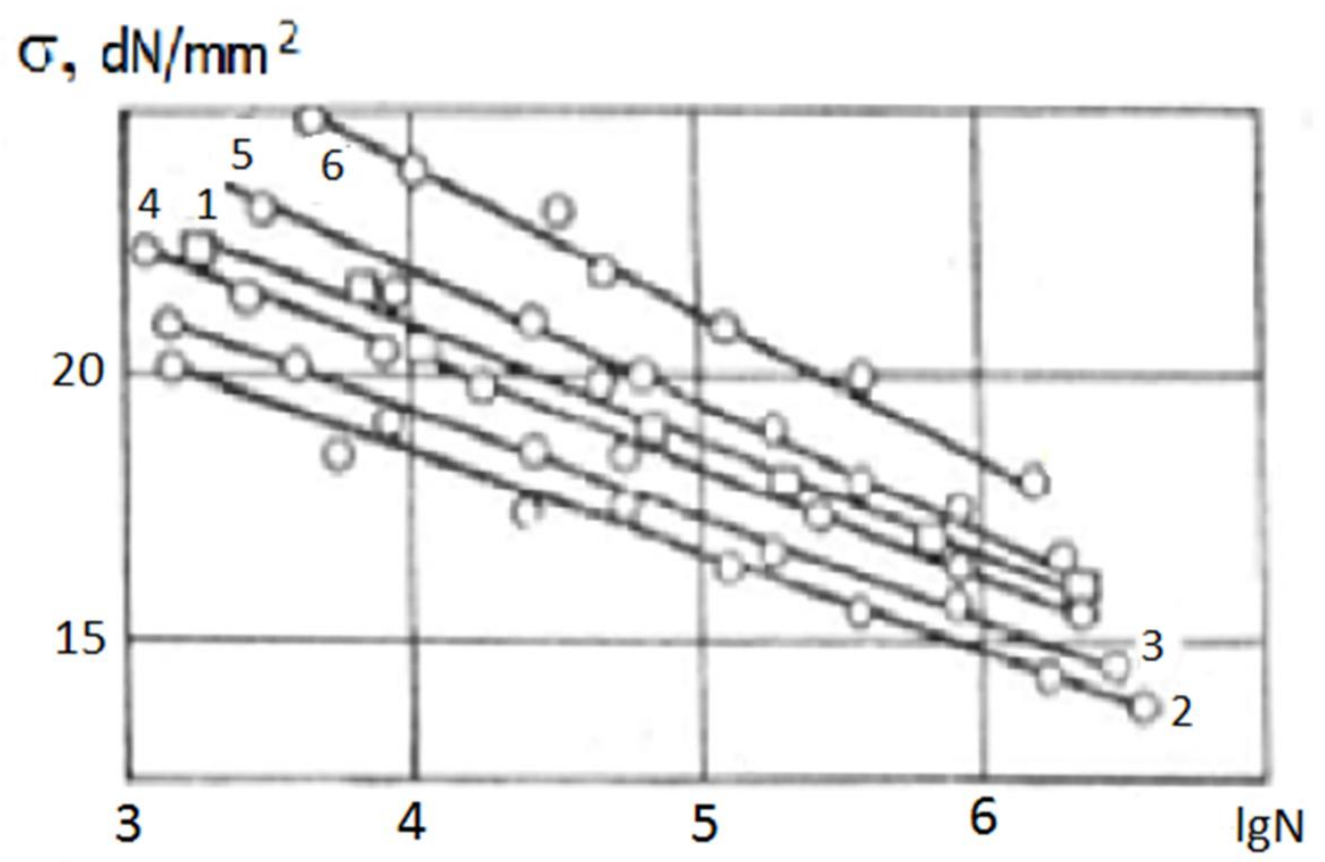

Figure 3. S-N curves for 12H!8N9T specimens after ECM at different current density I,A/cm2; 1-after grinding, $2-i=6 ; 3-i=10 ; 4-i=16 ; 5-i=25 ; 6-i=35$ [2]

It has been shown that the fatigue strength and endurance of stainless steel specimens are somewhat increased as more stock is removed by ECM, being a maximum when as much as 0.5 $\mathrm{mm}$ of stock is removed (as compared with ground specimens, Fig.4). 


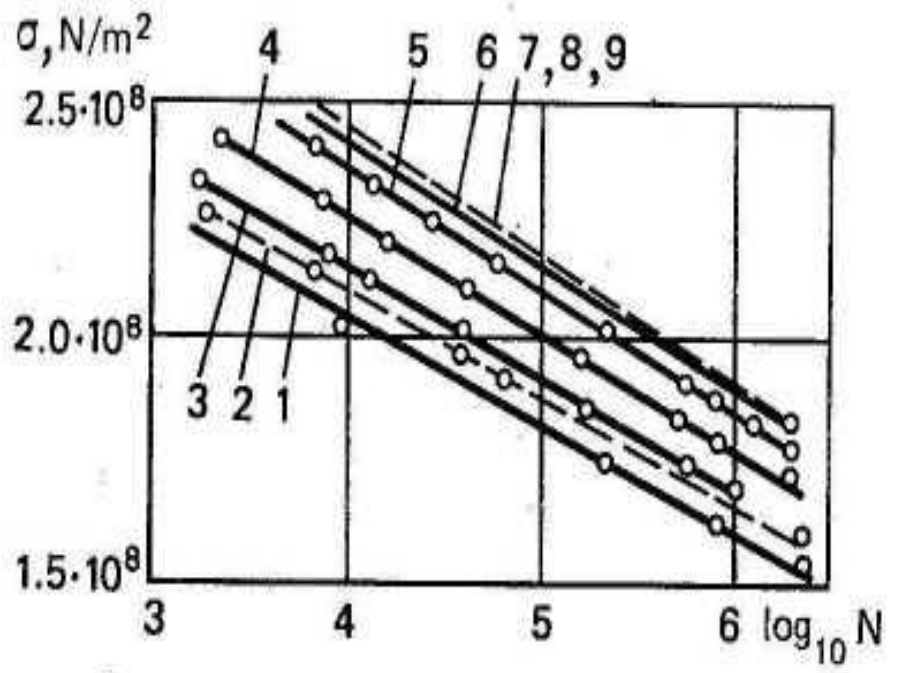

Figure 4. Fatigue strength of $18 \% \mathrm{Cr}, 9 \% \mathrm{Ni}, 1 \% \mathrm{Ti}$ alloy as a function of the amount of stock removed by ECM: 1-ground specimens;2 through 9-ECMed specimens with removed layer: 2-0.01 mm;3-0.03 mm;4-0.1 mm;6-0.5 mm;7-1 $\mathrm{mm} ; 8-2 \mathrm{~mm}$; and 9-3 $\mathrm{mm}[3]$

The fatigue limit is raised by $20 \mathrm{MPa}$. When as much as 0.25 to $1.5 \mathrm{~mm}$ of stock on side is removed, the height of surface irregularities remains unchanged, being about $0.2 \mu \mathrm{m}$ (the figure for ground specimens is 0.3 to $0.8 \mu \mathrm{m}$ ). No traces of electrolytic attack have been found at the grain boundaries under the ECM conditions used.

In the case of high-strength steels such as $0.3 \% \mathrm{C}-1 \% \mathrm{Cr}-1 \% \mathrm{Mn}-1 \% \mathrm{Si}-1 \% \mathrm{Ni}$ on which mechanical machining may leave burns and tool marks oriented at right angles to the load in mechanical tests, ECM improves their endurance and fatigue limit by 50 to $100 \%$ owing to avoidance of the above flaws. When steels like the one named above are electrochemically machined at low current densities and elevated temperatures, the metal surface is usually pitted, and the pits are likely to act as sites of incipient failure. Flaws like this should preferably be removed by vibratory finishing. Surface strengthening applied before such flaws have been removed may enhance the endurance only if the depth of the strain-hardened layer exceeds that of the pitted layer.

The main adverse effect of ECM on the strength properties of metals is associated with the nonuniform dissolution of individual alloy phases and, particularly, with intergranular attack. The nickel-base superalloys are prone to the intergranular attack (Fig.5).

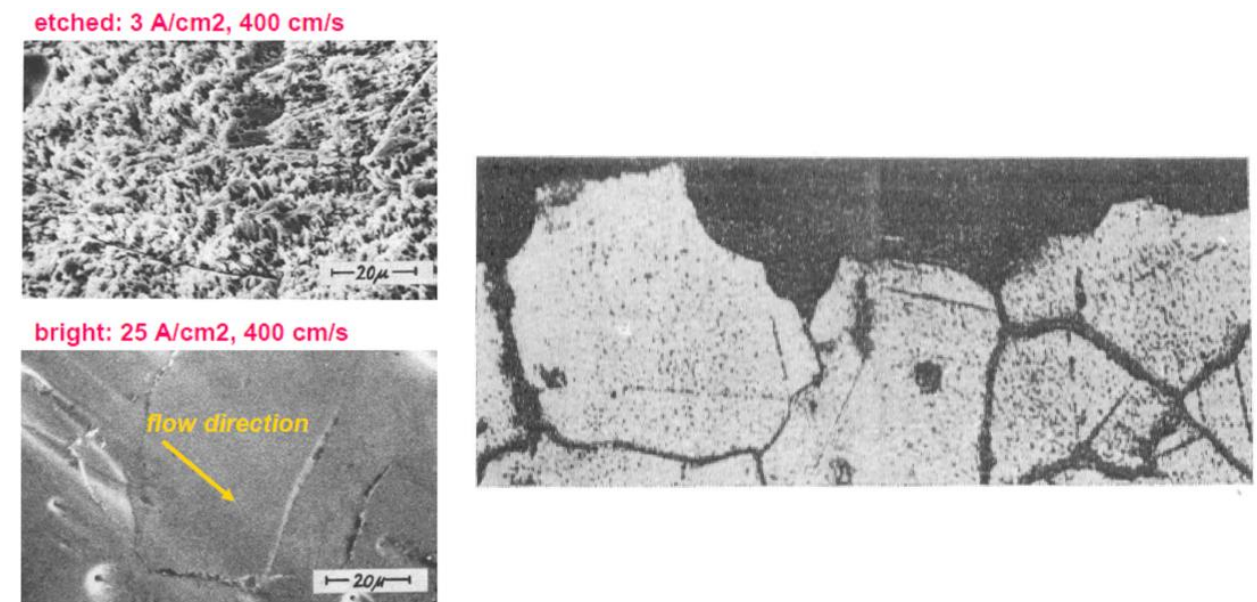

Figure 5. The surface erosion along the grain boundries (intergranular attack) of the nickel-base superalloys [1] 
The material at the grain boundaries may dissolve with higher or lower rate than the material of the grains, depending on the electrolyte composition and machining conditions such as current density (Fig.6).

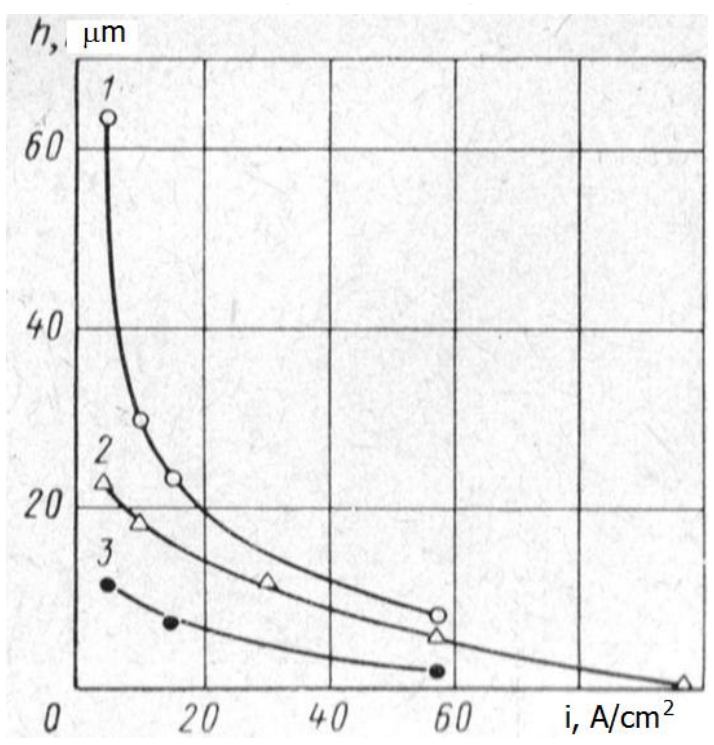

Figure 6. The depth of intergranular attack vs. current density for Nickel-Base Superalloys: 1-EI929;2-EI617 and 3-EI867 [2]

The height of asperities and the depth of erosion grow in magnitude with increasing temperature of the electrolyte. For one of such alloys electrochemically machined in a $10 \%$ $\mathrm{NaCl}$ electrolyte at a current density of $15 \mathrm{~A} / \mathrm{cm}^{2}$, the depth of erosion has been found to be 23 $\mu \mathrm{m}$ and $39 \mu \mathrm{m}$ at $24^{\circ} \mathrm{C}$ and $67^{\circ} \mathrm{C}$, respectively. The reduction in the fatigue strength of these steels and alloys as the temperature of the electrolyte is raised to $80^{\circ} \mathrm{C}$ can likewise be traced to changes in the quality of the surface layer (Fig.7).

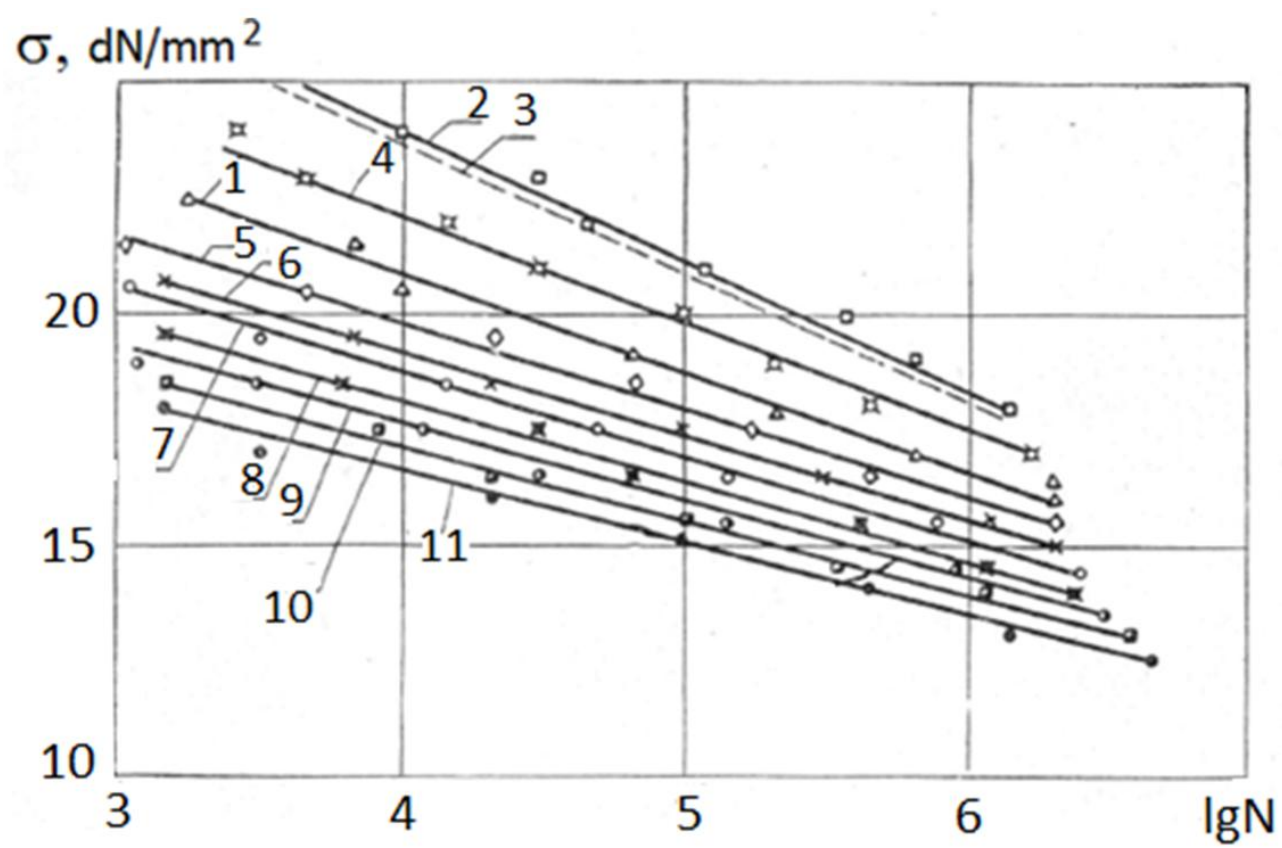

Figure 7. S-N curves for 12H18N9T specimens after ECM At different temperature of electrolyte: 1-after grinding; $2-\mathrm{T}=22^{\circ} \mathrm{C} ; 3-\mathrm{T}=27^{\circ} \mathrm{C} ; 4-\mathrm{T}=34^{\circ} \mathrm{C} ; 5-\mathrm{T}=47^{\circ} \mathrm{C} ; 6-\mathrm{T}=52^{\circ} \mathrm{C} ; 7-\mathrm{T}=57^{\circ} \mathrm{C} ; 8-\mathrm{T}=62^{\circ} \mathrm{C}$; 9- $\mathrm{T}=68^{\circ} \mathrm{C} ; 10-\mathrm{T}=72^{\circ} \mathrm{C} ; 11-\mathrm{T}=80^{\circ} \mathrm{C}[2]$ 


\section{The Effect of ECM on the Fatigue Strength of Titanium Alloys}

For some metals, especially for titanium, the hydrogen embrittlement of the surface layer was found after ECM. Titanium falls into a type of metals that absorb exothermically hydrogen and form stable hydrides. Therefore, the hydrogen embrittlement is observed after a great variety of action types, after different kinds of titanium machining. For a titanium-base alloy after ECM, the hydrogen content of a surface layer about $0.1 \mathrm{~mm}$ thick is several times greater than the hydrogen content of bulk metal. The association between the hydrogen embrittlement of titanium-base alloys in the ECM and the roughness of the machined surface has been found: the higher the roughness, the higher is the hydrogen content of the surface layer, Fig. 8. Therefore, the factors which cause a decrease in the roughness lead also to a decrease in the hydrogen embrittlement.

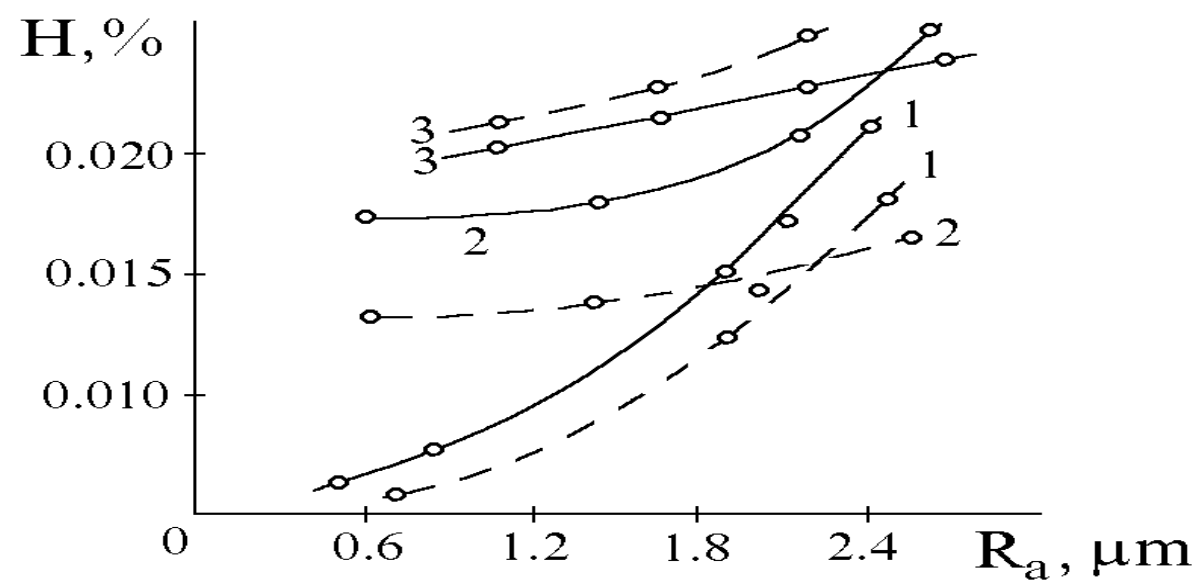

Figure 8. The plots of surface embrittlement of parts made of titanium-based alloys BT9 containing (solid lines) 6.5\% Al., 3.3\% Mo, $1.5 \% \mathrm{Zr}, 0.25 \% \mathrm{Si}$, and OT4-2(dotted lines) $6 \% \mathrm{Al}$. , $1.5 \%$ Mn versus the surface roughness Ra after the ECM in the solution of various electrolytes:

(1) $\mathrm{NaCl}+\mathrm{NH}_{4} \mathrm{NO}_{3}$, (2) $\mathrm{NaCl}+\mathrm{KBr}$, (3) $\mathrm{NaCl}[4]$

The observed relationship between values of the hydrogen $(\mathrm{H})$ content in the surface and average surface roughness Ra allows estimating $\mathrm{H} \%$ by measuring $\mathrm{Ra}$.

According to many investigations, the fatigue strength of titanium-base alloys decreases markedly after the ECM only under the conditions when the hydrogen embrittlement of the surface layer takes place. The negative effect of hydrogen generation on the fatigue strength, illuminated very clearly by curve 4 , was obtained from the experiment in which additional hydrogen was provided into the electrolyte (Fig.9).

The titanium-base alloy, which is electrochemically machined under the conditions when the intergranular attack occurs, has a significantly reduced strength. Strong pitting on the titanium samples has a similar effect. 


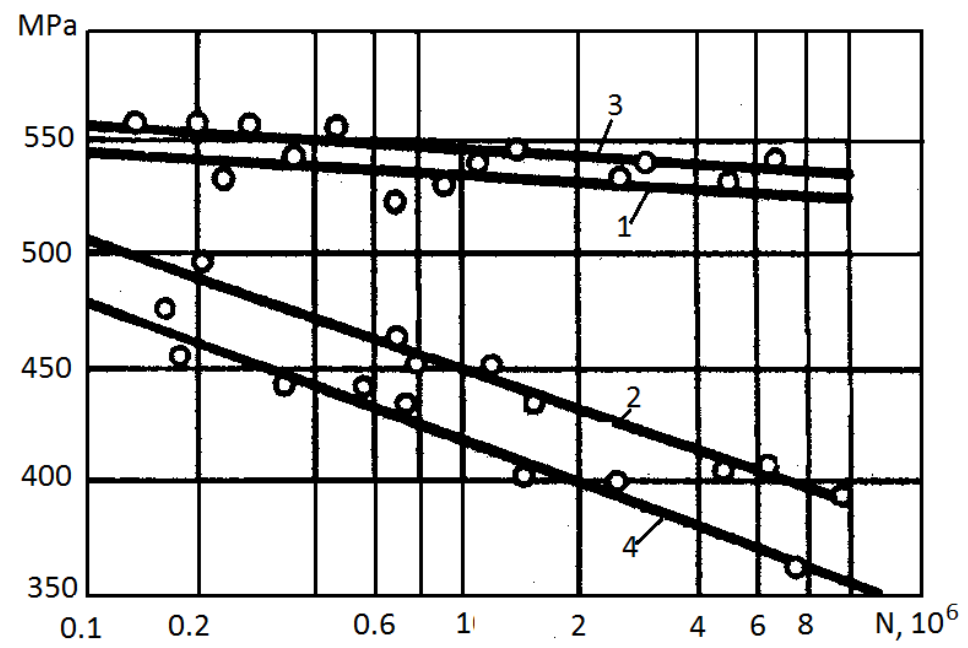

Figure 9.Fatigue strength curves for titanium alloy BT9 after ECM in: (1) $\mathrm{NaCl}+\mathrm{NH}_{4} \mathrm{NO}_{3}$, (2) $\mathrm{NaCl}+\mathrm{KBr}$, (4) $\mathrm{NaCl}+\mathrm{NH}_{4} \mathrm{NO}_{3}+\mathrm{H}_{2}$, and (3) after fine turning [4].

The fatigue strength depends on hydrogen embrittlement and surface roughness and can be expressed by statistical models as follows [4]:

$$
\begin{aligned}
& \sigma_{-1}=61.3-3.0 \cdot R a-1030 \cdot H \\
& \sigma_{-1}=52.2-3.6 \cdot R a-985 \cdot H
\end{aligned}
$$

where: $\sigma_{-1}$ is fatigue strength, $10[\mathrm{MPa}$ ], $\mathrm{Ra}$ is average surface roughness, $[\mu \mathrm{m}], \mathrm{H}$ is hydrogen content in surface layer, [\%].

There are several main methods for improving the surface layer integrity after ECM: the selection of electrolyte and machining conditions to eliminate intergranular attack, the removal (by mechanical turning, grinding, polishing, and chemical or electrochemical polishing) of a thin layer at least as deep as the grain-boundary etch $(0.02-0.2 \mathrm{~mm}$ for different materials), application of peening, shot-blasting, and other processes that are capable of inducing adequate compressive stresses in the surface.

Shot peening after ECM results in a substantial increase in the fatigue strength owing to the reintroduction of surface compressive stresses in the surface layer. After shot peening, the fatigue strength may be higher than that of the steel prior to ECM.

\section{SUMMARY}

The presence of intergranular attack in ECM of nickel base alloys and hydrogen embrittlement in ECM-ed titanium alloys resulted in the substantially reduced fatigue life of the machined parts. The better quality of the surface at higher current density leads to the increasing of the fatigue strength.

\section{REFERENCES}

[1] Landolt, D. (2009). The role of surface films in ECM. Proceedings of the International Symposium on ElectroChemical Machining Technology INSECT 2009, Dresden.

[2] Sedykin, F.N. (1976). Electrochemical machining of machine Components, (in Russian). Moscow: Mashinostrojenije.

[3] Rumyantsev, E. \& Davydov, A. (1989). Electrochemical machining of Metals. Moscow: MIR Publisher.

[4] Shmanilov, V.A., Filimoshin, V.G., Karimov, A.Ch., Petrov, B.I., \& Pronichev, N.D. (1986). ECM technology in production of airplane engines, (in Russian). Moscow: Mashinostroenie. 